\title{
Strategic management problems in Romanian small and medium-sized enterprises
}

\author{
Gina-Maria Moraru ${ }^{1, *}$, and Daniela Popa ${ }^{1}$ \\ ${ }^{1}$ Lucian Blaga University of Sibiu, Engineering Faculty, Industrial Engineering and Management Department, 4 Emil Cioran Street, \\ 550025 Sibiu, Romania
}

\begin{abstract}
The aim of the paper is to discover several of the strategic management problems that affect the most of Romanian small and medium-sized enterprises. The study presented here is only a part from a larger research developed by us during the last five years, research oriented towards sustainable development opportunities of these enterprises. Technological revolution, knowledge management and global expansion of big companies are just a few challenges to which small businesses have to cope. For this, their strategic management needs to take into account the turbulent business environment, to anticipate and to carry out correctly and in time the necessary changes in the organization. Unfortunately, our study has found gaps in the use of key strategic management tools and in the balanced use of resources in small Romanian firms.
\end{abstract}

\section{Introduction}

Strategy is the road on which organization goes after matching its internal resources and skills with the opportunities and risks from the external environment [1]. But, for elaboration of a good strategy, management should take into account that knowledge is nowadays the most important resource of an organization. That is why we propose to apply in the sector of small and medium enterprises (SMEs) the "Configuring for Knowledge" framework used in the institutional domain [2]. This closed loop framework has four essential steps $[2,3]$ :

- Identifying the strategic business drivers;

- Establishing the knowledge core, that includes both tangible and intangible assets (values, culture, people, technological intangible assets, business capabilities), and the knowledge interrelationships, for constructing a "knowledge value chain";

- Applying just-enough-discipline by focusing on knowledge culture and on speed and precision with which knowledge is disseminated;

- Monitoring and rebalancing the entire process.

Strategic management is the process of managing both the organization's mission and the relationship of the organization to its environment [4]. More and more firms, especially those of small and medium size, feel the need to develop formalized enterprising strategies [5]. This is the firs premise of our study.

The second one is the fact that European SMEs play a decisive role in the labour market [6]. By example, $0.2 \%$ of enterprises in the EU-28 non-financial business sector in 2016 were SMEs and employed 93 million people, respectively $67 \%$ of total employment in that sector [6]. Moreover, those firms generated $57 \%$ of value added in the EU-28 non-financial business sector [6].
And the third premise of our study is the fact that the European SMEs are facing many challenges of the business environment [6]. Technological revolution, knowledge management and global expansion of big companies are only a few of them. To this we can add the growing efforts that organizations need to make to assure their financial resources.

\section{Study for determine gaps in strategic management of SMEs}

The study presented here is only a part from a larger research developed by us during the last five years, research oriented towards sustainable development opportunities of SMEs. It aim was to discover several of the strategic management problems that affect the most of Romanian SMEs. The methodology of our study has combined the questionnaire technique with the interview technique. We have collected opinions of 40 managers working in SMEs from various fields, in Sibiu County, Romania (Fig. 1).

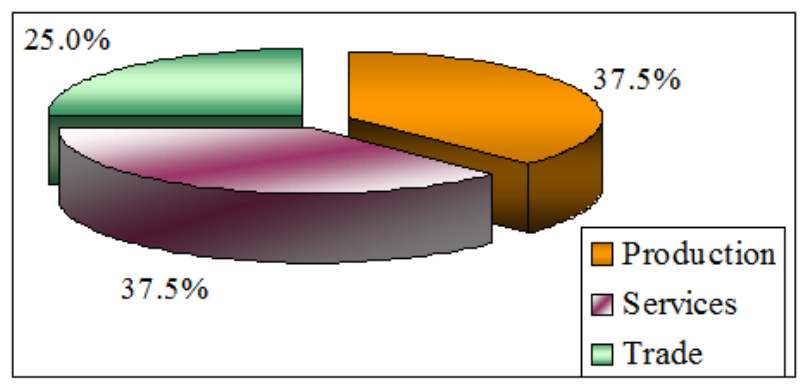

Fig. 1. Respondents' general fields of activity.

\footnotetext{
* Corresponding author: gina.moraru@ulbsibiu.ro
} 
We have firstly analyzed their opinion on the influence of environmental factors on their own strategies. Respondents' opinions on the current influence of factors in the general external environment on the business they lead are presented in Figure 2. Unfortunately, they do not foresee for the future any significant evolution of these influences on the studied organizations (Fig. 3).

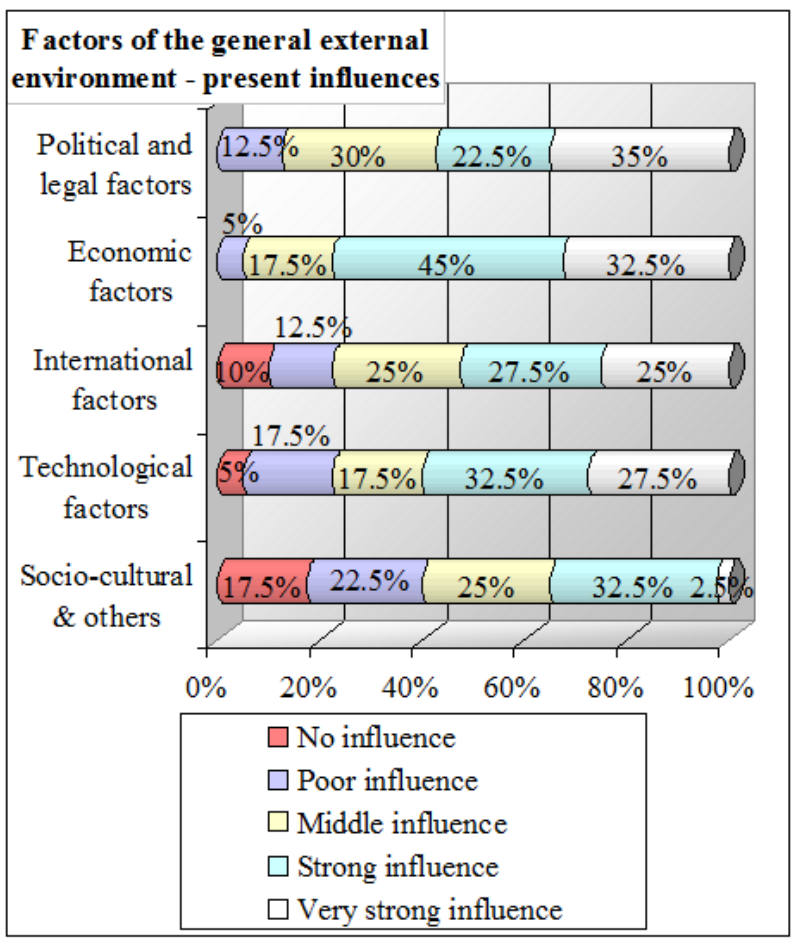

Fig. 2. Current influence of the general external environment on the studied SMEs and on their strategy.

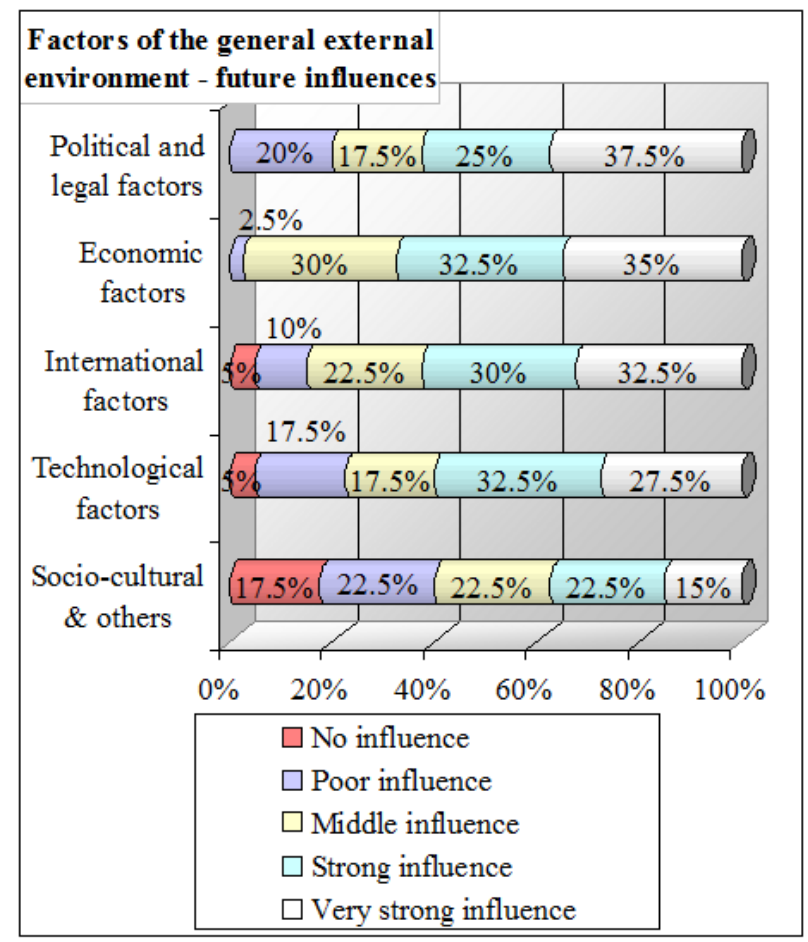

Fig. 3. Future influence of the general external environment on the studied SMEs and on their strategy.
These results (Fig. 2 and Fig. 3) determine us to affirm that SMEs' managers do not consistently monitor the factors of the external environment and do not perceive their increasingly intense turbulence. Moreover, we can conclude that SMEs' managers will build long-term strategies especially on the basis of legislative, political and economic influences, partly neglecting the others (Fig. 2 and Fig. 3).

Respondents' opinions on the current and futures influences of specific external environment on the SMEs are presented in Figure 4, respectively Figure 5.

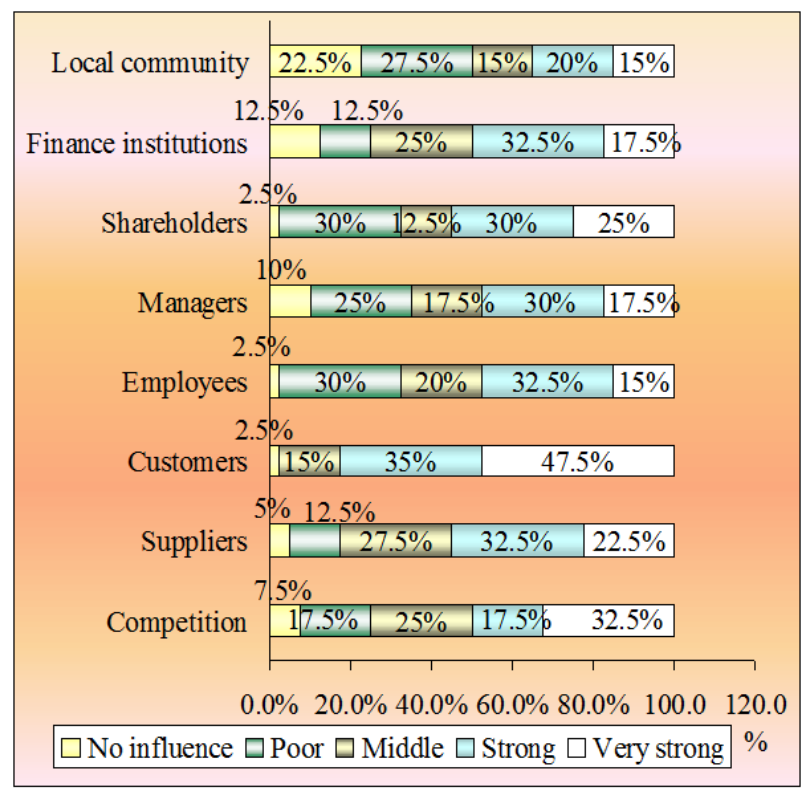

Fig. 4. Current influence of the specific external environment on the studied SMEs and on their strategy.

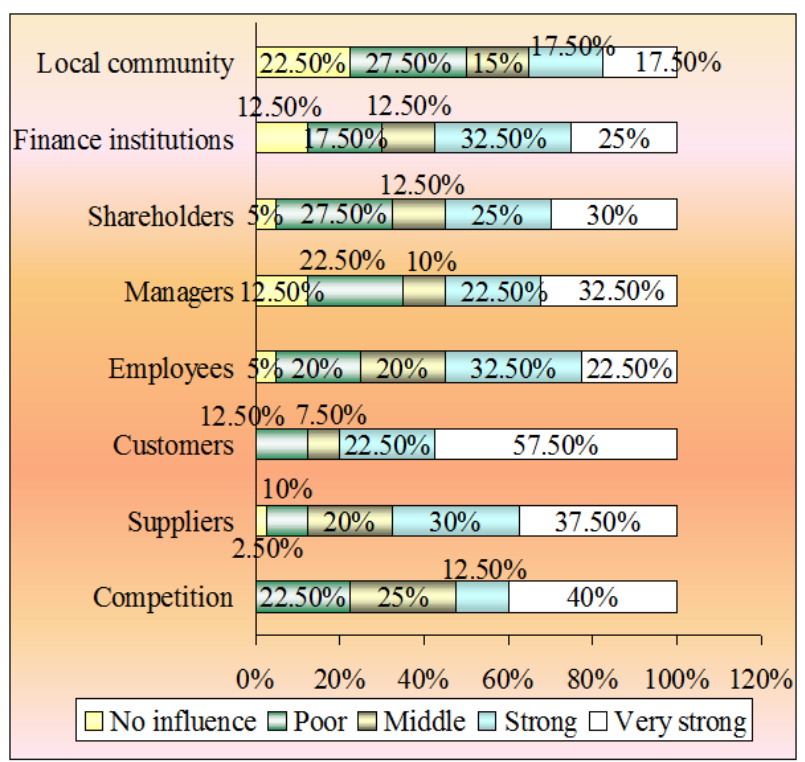

Fig. 5. Future influence of the specific external environment on the studied SMEs and on their strategy.

As we can see, respondents expect to increase in the future the impact of all factors in the specific external environment on SMEs (Fig. 5 versus Fig. 4). So, they are more interested in monitoring the specific external 
environment than in monitoring the overall external environment.

Regarding the impact of the classic resources (Fig. 6) and of the modern intangible ones (Fig. 7), we observe that our respondents do not perceive their crucial importance in developing the strategy. For developing and enhancing the knowledge in their organization, they will need to put more emphasis on intangible resources (Fig. 7) and to use them all in a more balanced way.

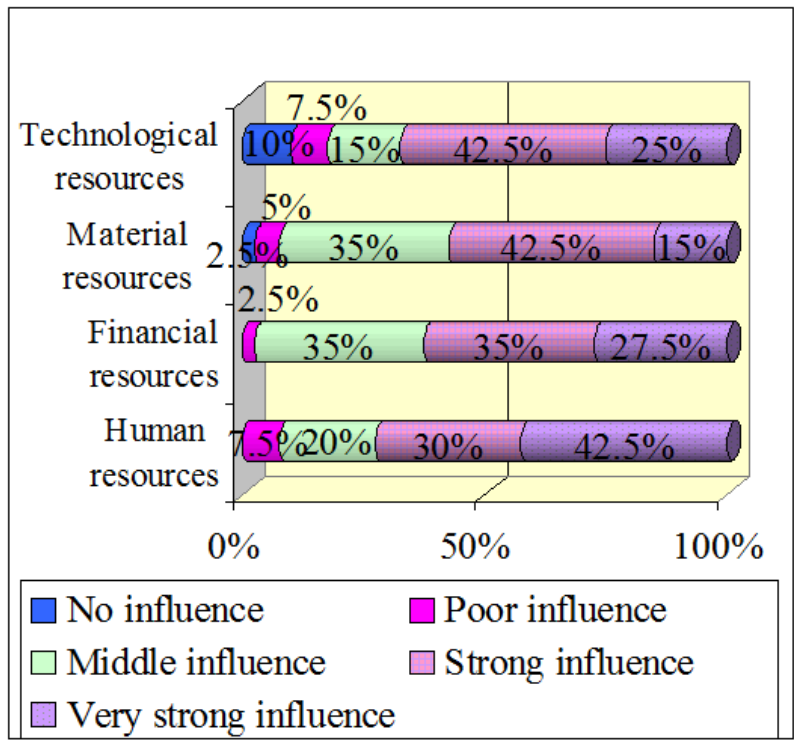

Fig. 6. The impact of the classic resources on the SMEs' strategies.

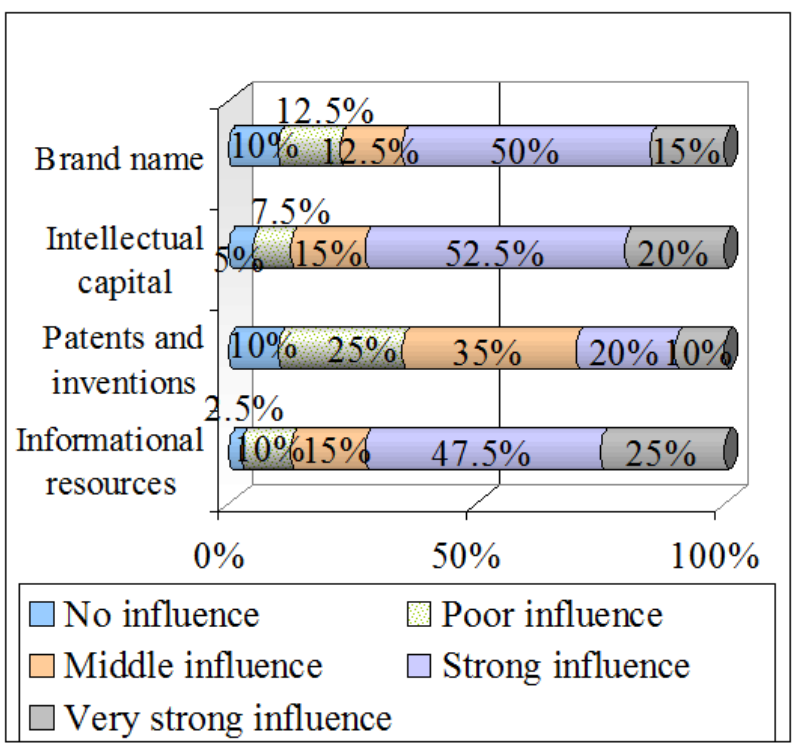

Fig. 7. The impact of the modern intangible resources on the SMEs' strategies.

In the second part of our study, we have questioned the respondents about the types of strategies they have used. Regarding the classification of competitive strategies, the situation of the responses by field of activity is presented in Figure 8.

Studying strategies according to the companies' development intentions, we find that $75 \%$ of them have adopted growth strategies (Fig. 9). We must say that most of them are in service and production.

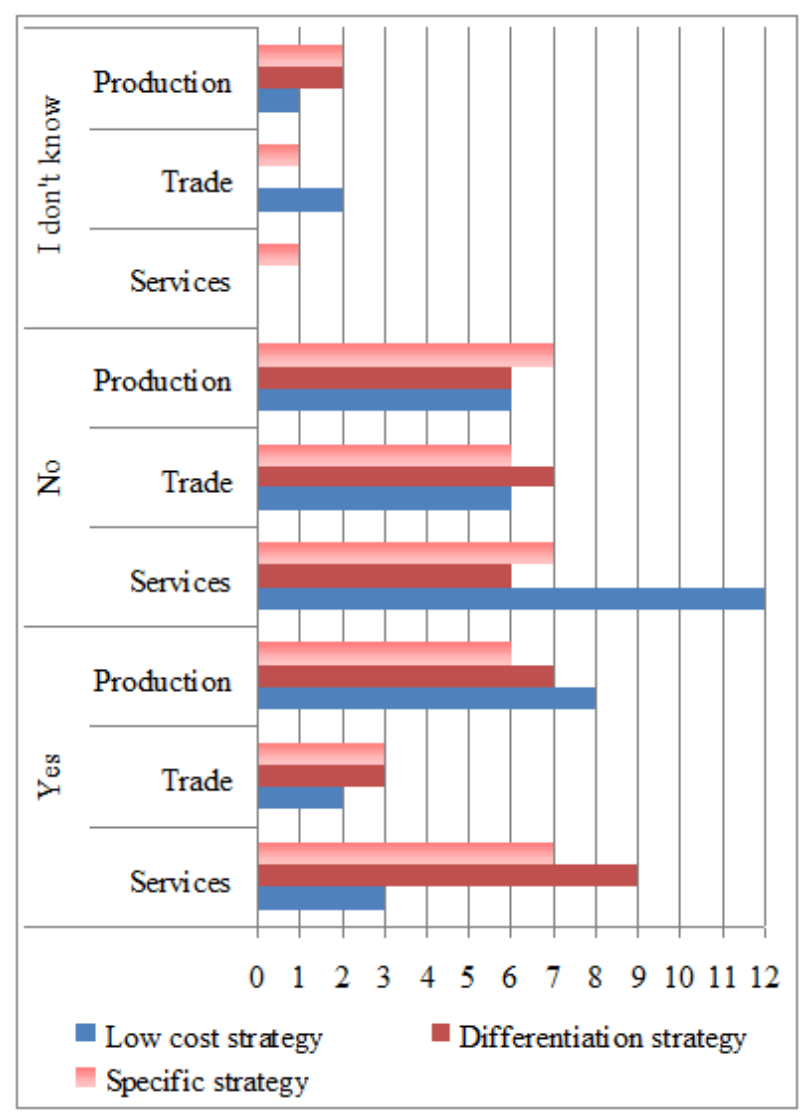

Fig. 8. Competitive strategies used by respondents in SMEs.

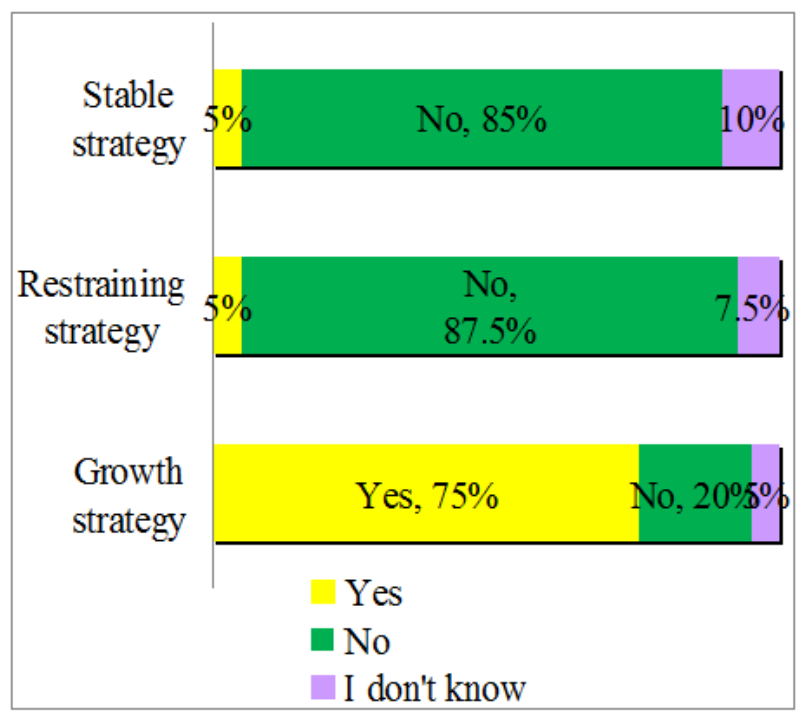

Fig. 9. Strategies adopted in SMEs regarding their development.

The largest share of businesses that have not adopted restraining strategies (Fig. 9) is found in the services sector, followed closely by the productive sector.

Responses to strategies adopted on the basis of the environment are centralised in Figure 10 . We note that prospective and analyzing strategies are predominant in 
SMEs. $42.5 \%$ of the companies turned to defense strategies, and $7.5 \%$ said they also adopted destructive strategies (Fig. 10).

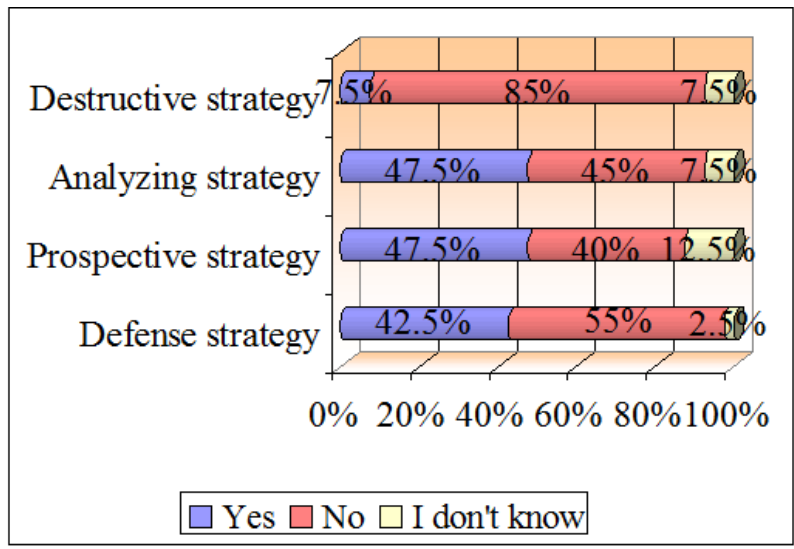

Fig. 10. Strategies adopted in SMEs on the basis of business environment.

Remaining in this classification of strategies, we have to mention that 10 firms in services field have adopt the analyzing strategy (Fig. 11).

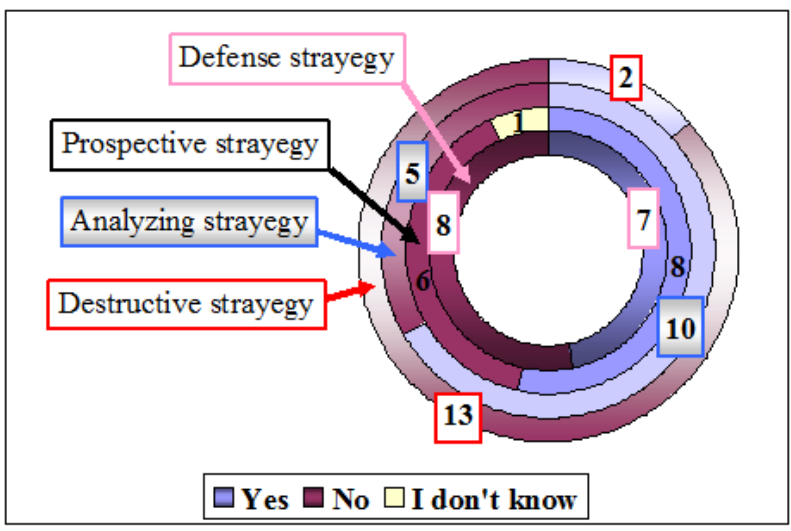

Fig. 11. Strategies adopted in SMEs in services field on the basis of business environment.

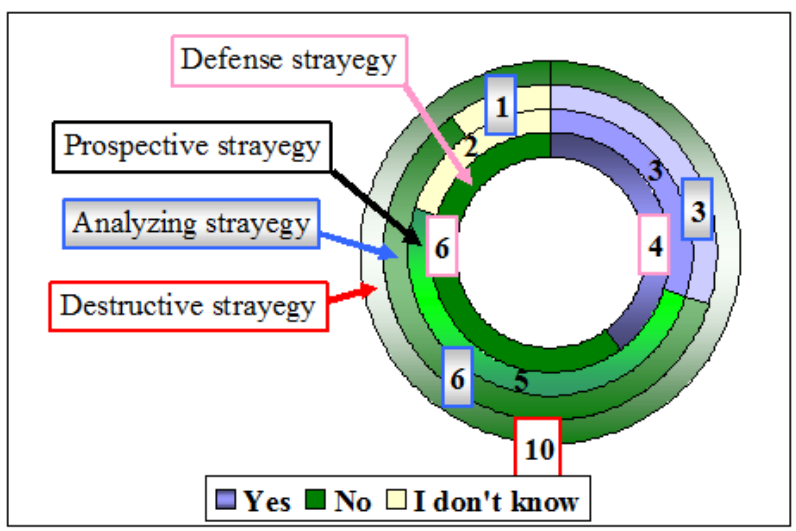

Fig. 12. Strategies adopted in SMEs in trade sector on the basis of business environment.
Only 3 firms in trade sector (Fig. 12) and 6 firms in production field (Fig. 13) have adopted the analyzing strategy.

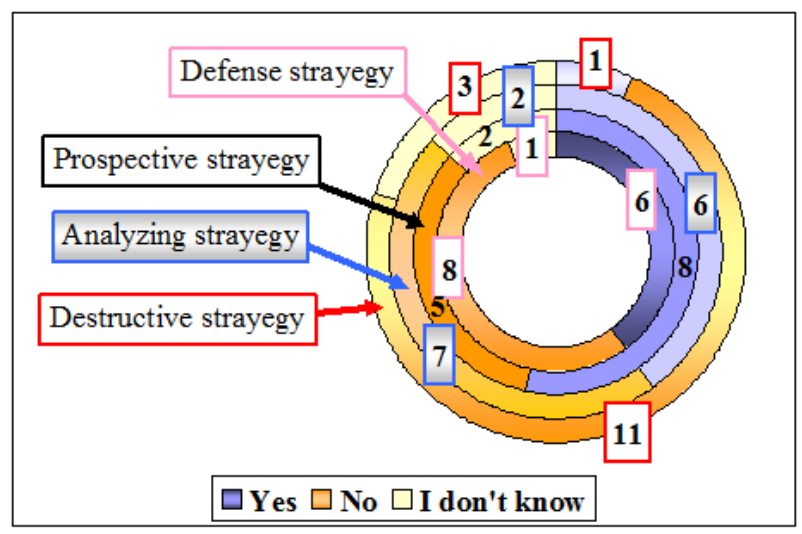

Fig. 13. Strategies adopted in SMEs in production field on the basis of business environment.

So, we can say that managers of services firms are better strategists than those in other areas.

\section{Conclusions}

Technological revolution, knowledge management and global expansion of big companies are just a few challenges to which SMEs have to cope. For this, their strategic management needs to take into account the turbulent business environment, to anticipate and to carry out correctly and in time the necessary changes in the organization. Unfortunately, our study has found gaps in the use of key strategic management tools and in the balanced use of resources in small Romanian firms.

\section{References}

1. R.M. Grant, California Mng. Rev. 33, 3, 114-135 (1991)

2. A.B. Graham, V.G. Pizzo, European Manag. J. 14, 4, 338-346 (1996)

3. L.A. Halawi, J.E. Aronson, R.V. McCarthy, Electronic J. Knowledge Manag. 3, 2, 75-86 (Academic Conferences Ltd, 2005)

4. J.M. Higgins, J.W. Vincze, Strategic Management: Texts and Cases (Dryden Press, New York, 1989)

5. O. Nicolescu, C. Nicolescu, Entrepreneurship and the management of small and medium enterprises (Intraprenoriatul si managementul intreprinderilor mici si mijlocii) (Economic Pub., Bucharest, 2008)

6. P. Muller, J. Julius, D. Herr, L. Koch, V. Peycheva, S. McKiernan, Annual Report on European SMEs 2016/2017. Focus on self-employment (European Commission, 2017) 